\title{
Optimization of resistance welding by using electric servo actuator
}

\author{
Zygmunt Mikno $^{1}$ D $\cdot$ Mariusz Stepien ${ }^{2} \cdot{\text { Boguslaw } \text { Grzesik }^{2}}^{2}$
}

Received: 23 September 2016 / Accepted: 4 February 2017 / Published online: 21 February 2017

(C) The Author(s) 2017. This article is published with open access at Springerlink.com

\begin{abstract}
The paper is focused on the control of resistance projection welding process applied in joining of thin-walled metal elements. The motion of electrode is generated by electric servo actuator that controls the force exerted on electrode or alternatively, just travel itself of electrode. The projection welding has been discussed for welding of 1.5 mm thick DX53 steel sheets where one sheet contains an embossed projection. Apart of electric servo actuator, another source of force has been described, i.e. pneumatic actuator (classical one), for the reason of comparison. The solution where the electric servo operates together with appropriate algorithm makes the new solution that is alternative for classical, pneumatic one. Optimized motion of electrode due to new proposed source of electrode force or/and travel, based on relevant algorithm yields improved quality of joints.
\end{abstract}

Keywords (IIW Thesaurus) Resistance welding · Pneumatic equipment · Optimization · Projection welding . Electrode force

Recommended for publication by Commission III - Resistance Welding, Solid State Welding, and Allied Joining Process

\author{
Zygmunt Mikno \\ zygmunt.mikno@is.gliwice.pl \\ Mariusz Stepien \\ mariusz.stepien@polsl.pl \\ Boguslaw Grzesik \\ boguslaw.grzesik@polsl.pl \\ 1 Welding Institute, Gliwice, Poland \\ 2 Silesian University of Technology, Gliwice, Poland
}

\section{Introduction}

Resistance welding is one of the primary methods used for joining thin-walled elements in the automotive, building engineering, electrical engineering, household equipment manufacturing and aviation industries.

The technology of resistance welding has been known and developed for almost 140 years (the first resistance welded joint dates back to 1877) [1]. The popularity of resistance welding results from its three both practical and economical advantages, i.e. (i) no need to use filler metals, (ii) short processing time (current flow time of approx. $200 \mathrm{~ms}$ ) and (iii) low cost of energy per one joint (approximately 0.1 US cent). The information presented above refers to the overlap welding of 1-mm thick sheets.

As the cost of the energy mentioned above may seem unreliable, the information presented in Table 1 includes figures related to the cost of electric energy drawn from the power grid in order to power a welding machine when making a welded joint of two sheets ( $1.0 \mathrm{~mm}$ thick each).

When calculating the energy-related costs, it was assumed that the power efficiency of a welding machine amounted to $6 \%$ (i.e. relatively low in the example analysed above) and that the average cost of electric energy in the USA was $0.12 \$ / 1 \mathrm{kWh}$ [2]. The remaining data used in the calculations were determined experimentally using a DC 250 kVA ZPI90 inverter welding machine $(1 \mathrm{kHz})$ manufactured by the ASPA Wroclaw and Welding Institute, Poland (throat depth of a welding machine amounted to $800 \mathrm{~mm}$ and window height of $450 \mathrm{~mm}$ ).

The necessity of making a large number of, mostly overlap, joints when manufacturing a car body (i.e. between 3000 and 5000 welds, depending on the type of a body) is responsible for the popularity of resistance welding in the automotive industry [1]. 
Table 1 Costs of electric energy for welding 1.0-mm thick sheets

\begin{tabular}{lllllllll}
\hline$I$ & $U$ & $t$ & Energy & & Cost of $1 \mathrm{kWh}$ & Efficiency & Total cost \\
\hline Of welding & & & & & & & & \\
$\mathrm{kA}$ & $\mathrm{V}$ & $\mathrm{ms}$ & $\mathrm{Ws}$ & $\mathrm{Wh}$ & $\$$ & $\%$ & $\$$ & $\$$ cent \\
8 & 1.5 & 200 & $2.4 \mathrm{k}$ & 0.67 & 0.12 & 6.0 & 0.0013 & 0.13 \\
\hline
\end{tabular}

Advantages resulting from the use of the electric servo system are (i) no need for a compressed air system, (ii) the reduction of noise and (iii) significantly faster travel of electrodes.

However, the use of the servo operating force system requires that the operating personnel perform additional preparatory activities before welding, i.e. (i) adjusting the geometrical zero of electrodes after each exchange and refurbishment of electrode terminals and (ii) creating the table of calibration, i.e. correlation between the servo actuator input current and the actual force of welding machine electrodes.

An important aspect, in terms of the quality of welded joints, is the control of a force and/or travel by electric servo actuator ensuring the repeatability and changeability (when necessary) of welding processes. Such control should lead to the optimization of welding power spatial distribution in the welding area and, consequently, to the improvement of welded joint quality.

The force and electrode travel control during the resistance welding process described in the paper is totally different than control processes used so far, and it influences on existing point of view concerning resistance welding. Advantages of novel solution are visible particularly for relatively large electrode travel distance during the current flow, such as can be observed during projection welding. Presented in the paper method is still ongoing. It has been verified experimentally based on examples of projection welding of sheets (embossed projection) and cross-wire.

\section{Welding machine characteristics}

A simplified diagram of a welding machine system is presented in Fig. 1. It consists of the following parts: (i) three-phase grid rectifier (GR, D1-D6) with a capacitive filter (Cf), (ii) inverter (Iv) based on IGBT transistors (T1-T4), (iii) transformer (Tr) with an output rectifier (OR, D7-D8) and (iv) electrodes with a pneumatic/electric servo actuator. The operation of the inverter is controlled and monitored by a control system $\mu \mathrm{P}$.

One can observe that an electric energy is converted in the welding machine four times. First, the input energy of alternating current of the grid $(50 / 60 \mathrm{~Hz})$ is converted in the input rectifier into a DC energy and filtered by capacitor $\mathrm{Cf}$. Afterwards, the DC energy is converted in the inverter into the AC energy of medium frequency $(1 / 10 \mathrm{kHz})$ [3]. At the third stage, the transformer transforms the energy to the high current energy. And the last step, it is rectified by the fullwave two diode output rectifier. Such DC energy is delivered to the welded elements and converted into thermal energy.

The amount of energy delivered to the weld is controlled by the inverter, where the transistors are controlled by appropriate duty ratio $\mathrm{D}$. The average value of welding current is proportional to duty ratio $\mathrm{D}$. Such a solution is typical in inverter welding machines used in resistance welding.

The control of welding current (the amplitude, the duration and the shape) doses the amount of the energy supplied to the welding area. But it is not only one parameter
Fig. 1 Power ciruits of inverter welding machine, GR - grid rectifier, $\mathrm{Cf}$ - filter capacitor, Iv - inverter, OR - output rectifier, CS - DC current sensor, F electrode force

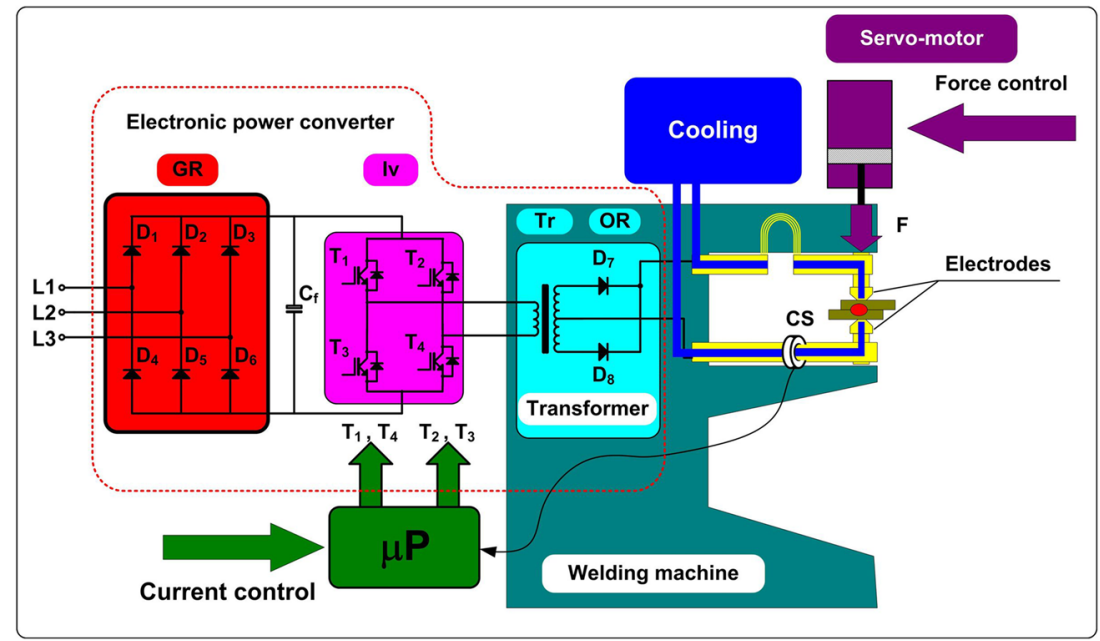


controlling the energy. The second one, of great importance, is the control of the force that electrodes exert on welded elements-it is a separate technological problem to be solved. The energy is controlled by the force of electrodes because it influences directly on the resistance of welded elements (the energy is a product of time, square of current and the resistance). The same can be considered taking the power into account.

$E=I^{2} \times R \times t$

The optimization of a welding process, defined as the control of welding energy and power spatial distribution, is greatly affected by the use of an electric servo force system and by the application of appropriate control algorithms. Successful optimization process results with improved repeatability and, consequently, in the better quality of welded joints $[3,4]$.

\section{Areas of application}

As was mentioned, the advantages of new solution take place, particularly for projection welding, where the technological process is characterized with relative large electrode travel distance during the current flow (e.g. in comparison with resistance overlap spot welding of sheets). The paper is concerned with one variant of resistance welding, i.e. the projection welding of sheets with embossed projections. Basically, the projection welding (including mentioned embossed projection welding) is used when it is necessary to make several joints at the same time, produce aesthetic joints without indents visible in the material due to force exerted by electrodes and to obtain the small heat-affected zone. The quality of welded joints and the repeatability of process are very important in the most of applications. For example, modern car bodies contain approximately 300 fasteners, e.g. bolts, nuts and pins, punched and welded using the technology described in this paper. Key elements, such as the front and rear car axles, are mounted to such fasteners; the seat belts and the steering column are anchored to them and provide grounding for electric wires. The quality with which such fasteners are attached to the stamped elements of the car body is of critical importance as regards the safety and reliability of the finished product [5].

The tests described in [6] and [7] revealed numerous drawbacks of projection welding related to the application of the pneumatic force system. The most important disadvantages are narrow windows of welding parameters, the lack of process repeatability and, as a result, the deterioration of quality [8]. The change of a projection height plays the crucial role during the initial heating of the projection welding process. The beginning of the welding process is often accompanied by the formation of a ring weld nugget and expulsion at the perimeter of the contact area $[6,7,9]$. In dynamic welding processes, e.g. capacitor discharge welding [10] or the welding of aluminum [11], due to a short current flow time, it is necessary to ensure high dynamics of force changes. The primary reason for the disadvantages described is the use of the pneumatic force system characterized by high mechanical inertia and the lack of force control possibility, particularly during the flow of welding current [12].

Alternatively, it is possible to use the electric servo force system whose advantages when carrying out resistance welding have been discussed in reference publications, e.g. [9]. However, the authors of the aforementioned papers used only one of the possible options related to electric servo system control, i.e. control in relation to force control algorithm $[13,14]$. There is another option of the electric servo control system, highly useful during welding, i.e. the control of electrode travel, presented and discussed by the authors of following publication $[4,9,15,16]$.

\section{FEM numerical analysis}

\subsection{FEM computational model}

The computational model is shown in Fig. 2. The process of optimisation has been carried out for resistance welding, i.e. for the projection welding of sheets with an embossed projection. The investigation-related FEM calculations has been performed using a commercial software SORPAS [17]. The software performs sequential conjugate calculations of electric, thermal and mechanical models.

The welding technology parameters related to the computational model have been determined using applied standards as follows: (i) welding current $I=10 \mathrm{kA}$, (ii) rise time (up-slope) $60 \mathrm{~ms}$ plus primary welding time $240 \mathrm{~ms}$, (iii) force $F=1.1,2.2,4.4$ and $5.5 \mathrm{kN}$ for the pneumatic system, (iv) control of electrode force and/or travel, (v) projection geometry type $\mathrm{C}$ (shape and dimensions c.f. Fig. 2) $[18,19]$.

\subsection{FEM numerical calculations}

The FEM calculations have been performed for the same welding conditions (parameters) $(I=10.0 \mathrm{kA}$, rise time $60 \mathrm{~ms}$, primary welding time $240 \mathrm{~ms}$ ) but for various welding machine electrode force systems.

The key quantities as regards the optimization of projection welding processes, i.e. electrode travel profiles for the pneumatic and electric servo system are presented in Fig. 3. The most significant differences are related to the value of "cold" projection height reduction, i.e. before the flow of welding current and to the value of projection height reduction time during the flow of current. 
Fig. 2 Geometry of computational model, including meshing and selected projection dimensions

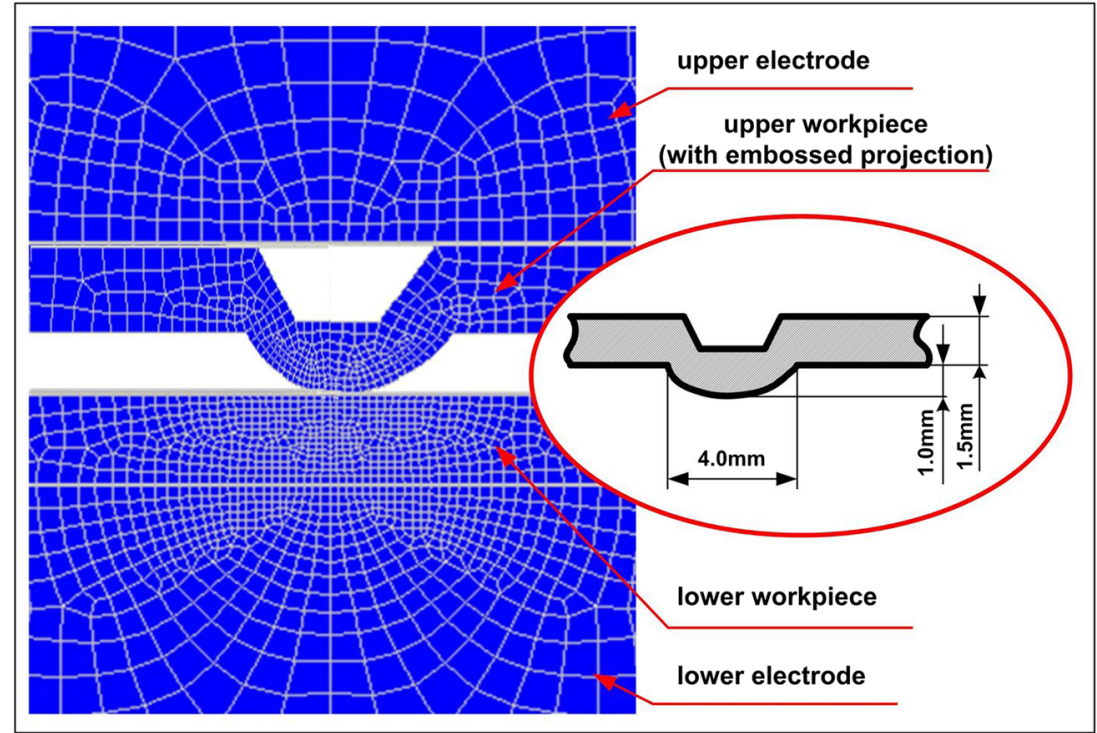

The computational model enabled the analysis of additional, yet important process quantities such as the resistance of the contact area between elements being welded, welding power waveform and temperature distribution in the welding area (materials being welded and electrodes).

\subsection{Results of FEM calculations}

The following results have been obtained by the numerical calculations:

- Electrode travel profiles (projection height reduction) for the classical (pneumatic) and new (electric servo) force systems (Fig. 3)
- Waveform of contact area resistance (projection-the sheet without the embossed projection) and of instantaneous power (Fig. 4)

- Temperature distribution in the welding area for the pneumatic and electric servo system (Fig. 5)

- Profiles of force and electrode travels for the classical (pneumatic) and new (electric servo) force system (Fig. 6)

\subsection{Analysis of FEM results}

In terms of the best welding conditions (BWC), the cold projection height reduction for the pneumatic system (hPc-height, pneumatic, cold work) is amounted to 0.45
Fig. 3 FEM results of electrode travel (change in projection height reduction) during welding time for pneumatic force system and the following parameters: initial force time $t_{\text {init }}$ orce $=100 \mathrm{~ms}$, welding current $i_{\text {weld }}=10 \mathrm{kA}$, welding time $t_{\text {weld }}=60 \mathrm{~ms}$ (up-slope)+240 ms and electrode force $F=2.2 \mathrm{kN}$ and electric servo system for the same energy parameters (current and time)

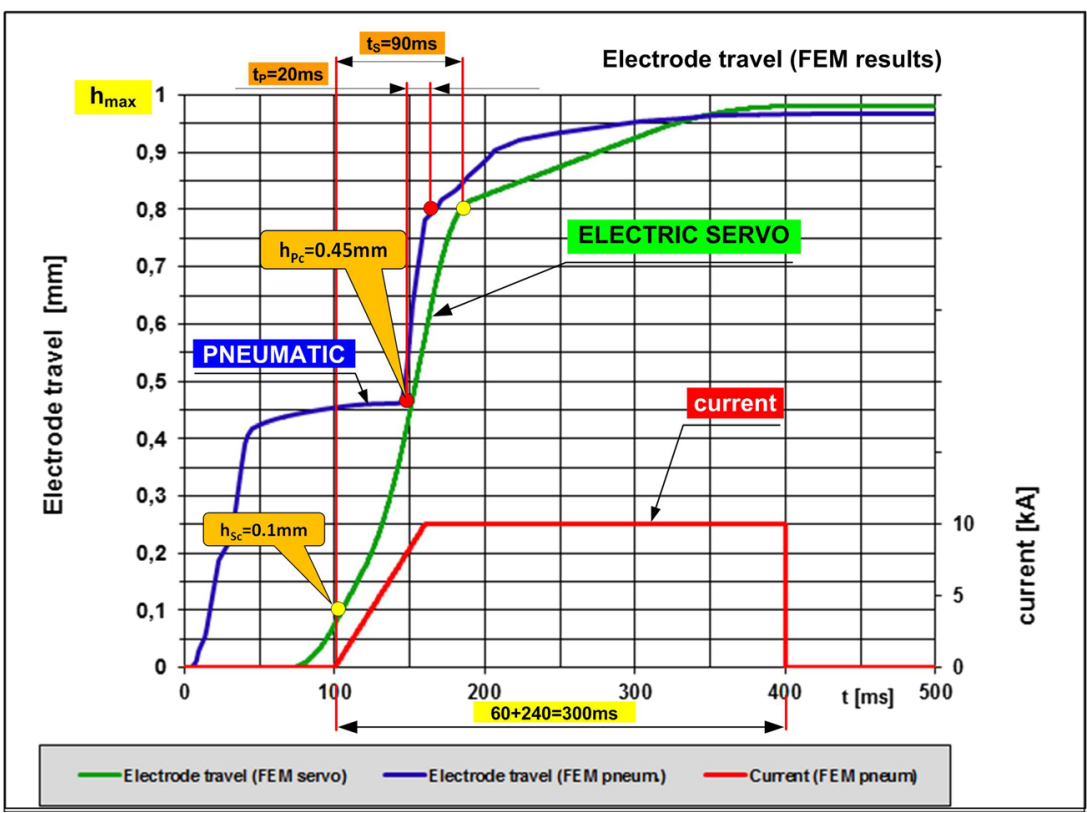


Fig. 4 Waveforms of total contact resistance (a) and instantaneous power (b) for pneumatic and electric servo system; welding current presented as a reference

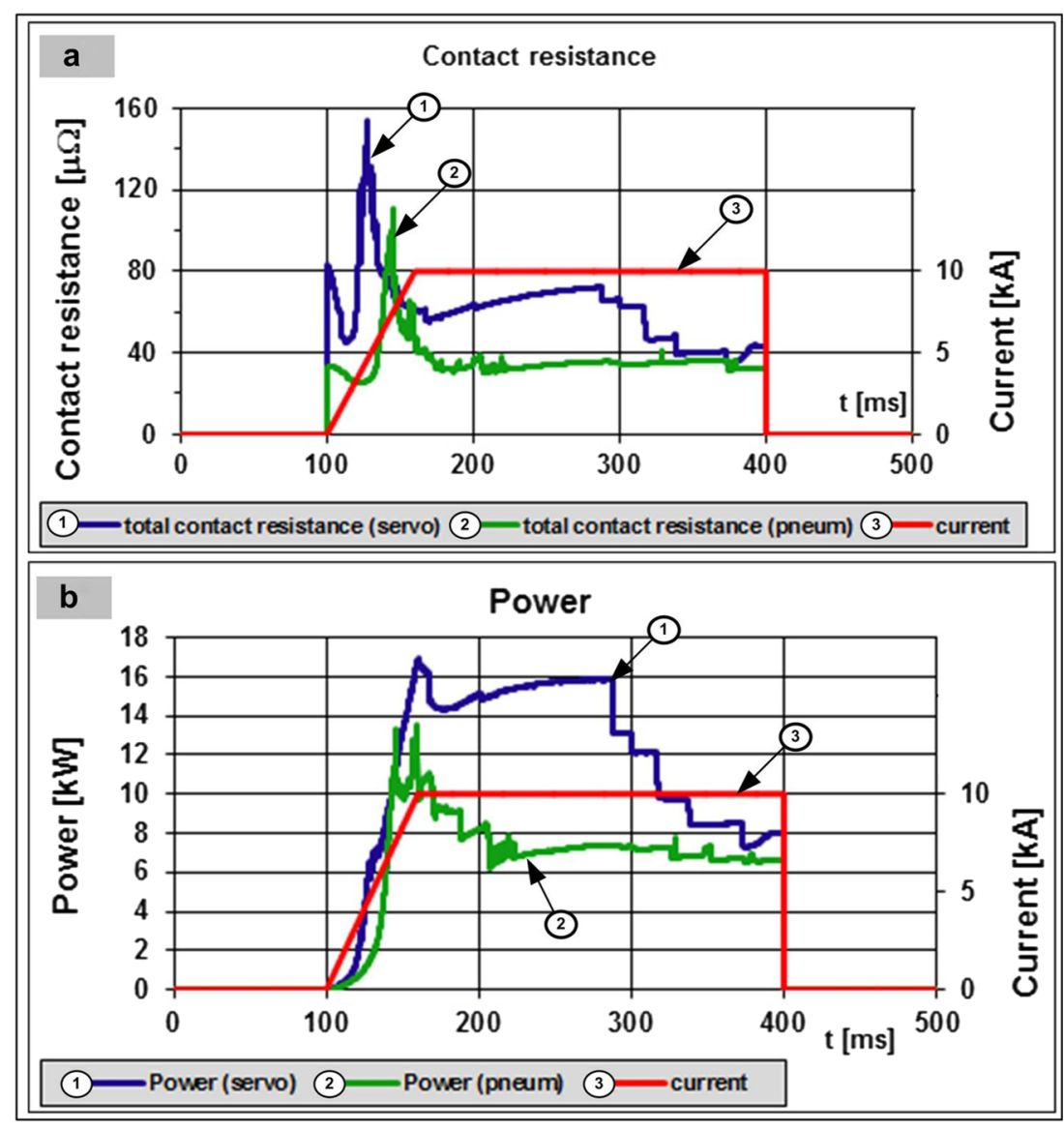

mm (45\% of hmax) (c.f. Fig. 3). In comparison with the electric servo system, this value is excessively high and negatively affected the further course of the welding process. It is possible to observe the formation of a ring weld nugget which, in practice, do not always transform into a fully shaped (i.e. oval) weld nugget (Fig. 5a). In turn, in the case of the electric servo system, the cold projection height reduction ( $\mathrm{hSc}$ - height, electric servo, cold work) is amounted to $0.1 \mathrm{~m}$ (10\% of hmax) (c.f. Fig. 3) and the weld nugget is initially formed in the center and expand outwards.

In the case of the pneumatic force system (Fig. 6a1) and for the significant projection height reduction taking place at the beginning of the process, the area of contact between elements being welded (i.e. the projection and the flat sheet without the projection) is relatively high. Therefore, the resistance of the contact area is low (c.f. Fig. 4a, curve no. 2) and, as a result, the generated power and, ultimately, the energy is lower (c.f. Fig. 4 b, curve no. 2). In turn, for the electric servo system, the value of the contact resistance is higher (Fig. 4a, curve no. 3) and, consequently, the generated power, and energy, are higher (Fig. 4b, curve no. 3).

Due to the significant inertia of the pneumatic force system, during the flow of welding current, the projection material underwent plasticisation and there is no possibility to control the force of electrode and, as a result, it is impossible to influence on the time of projection height reduction.

Both the first (i.e. significant cold projection height reduction) and the second (i.e. the lack of force control possibility) disadvantageous factor in the projection welding of sheets with an embossed projection resulted from the use of the pneumatic force system. During the whole process, the force is constant and, at the same time, excessively high. It is not possible to control the force during welding, which is due to an overly short welding time (current flow time of $300 \mathrm{~ms}$ ) and because of the high inertia of the moving electrode. As a result, the cold projection height reduction is excessive, whereas the time of projection height reduction during welding (current flow time) is overly short (20 ms). Consequently, the time when energy is generated at the most appropriate area is overly short as well. After the entire projection height reduction, the area of contact between elements being welded is improperly large and welding current density decrease dramatically. As a result, the process of material melting and that of the weld formation are strongly impede and, in cases of higher force values, even impossible. 


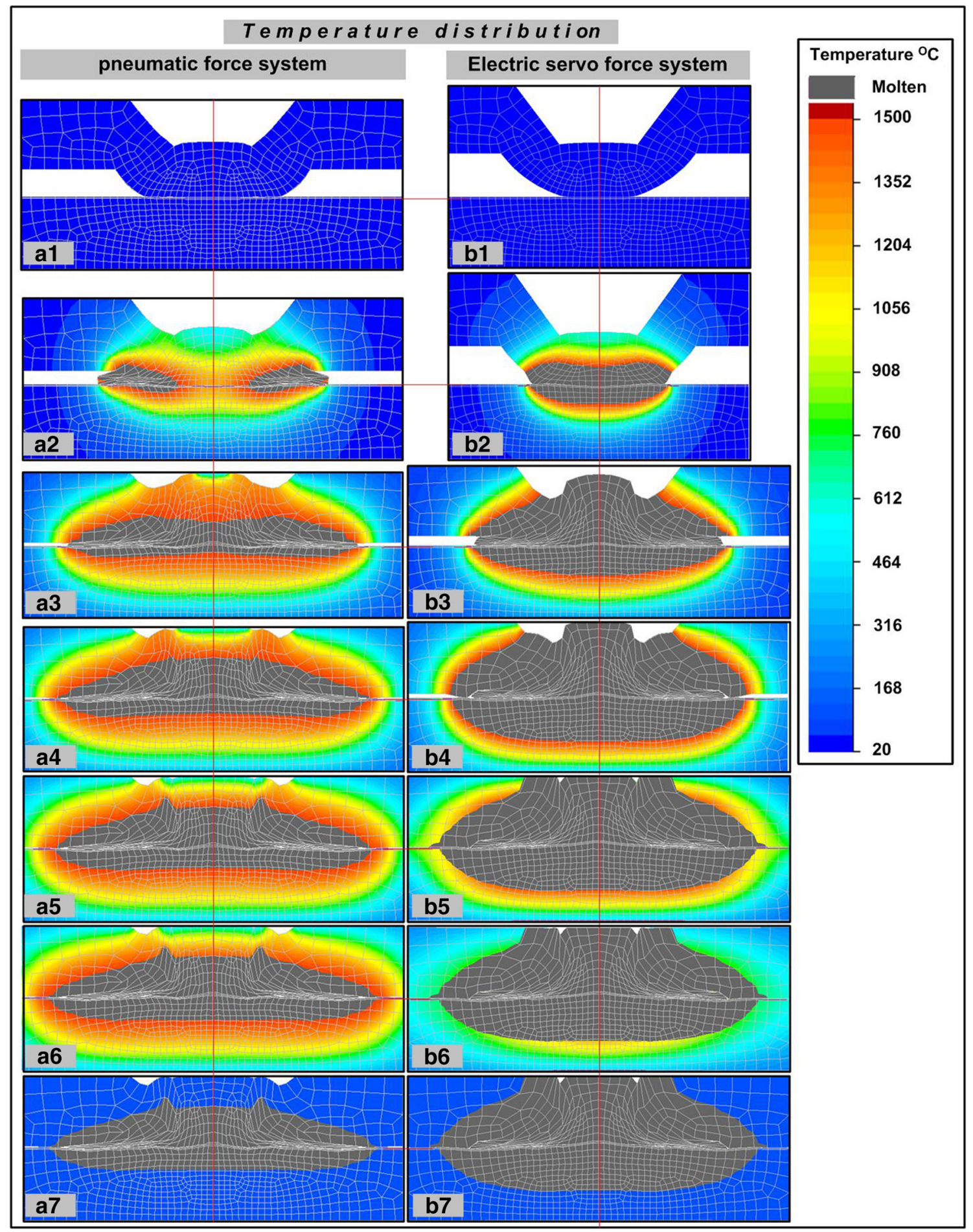

Fig. 5 Temperature distribution: $a 1)-a 7$ ) for the pneumatic force system and $b 1)-b 7)$ for the electric servo system: $a 1) / b 1$ ) at the beginning of current flow, $a 2) / b 2$ ) at $60 \mathrm{~ms}$ of current flow, $a 3) / b 3$ ) at $120 \mathrm{~ms}$ of

When welding is performed using the pneumatic force system, the preset electrode force results in the travel of electrodes (c.f. Fig. 6a).

The optimization of the welding process consisting in changing the value of a preset quantity (i.e. the control of current flow, a4)/b4) at $180 \mathrm{~ms}$ of current flow, $a 5) / b 5$ ) at $240 \mathrm{~ms}$ of current flow, $a 6) / b 6$ ) at $300 / 330 \mathrm{~ms}$ (pneumatic/electric servo system) of current flow, $a 7) / b 7$ ) $2 \mathrm{~s}$ after the stop of current flow

electrode travel) instead of electrode force (particularly during the flow of welding current) enables the obtainment of very advantageous changes. As a result, the distribution of temperature in the welding area is significantly more convenient (c.f. Fig. 5b), particularly at the beginning of 
Fig. 6 Waveforms of force and electrode travel obtained by FEM calculation for a pneumatic force system and $\mathbf{b}$ electric servo system; preset and resultant parameters are marked, welding current presented as a reference
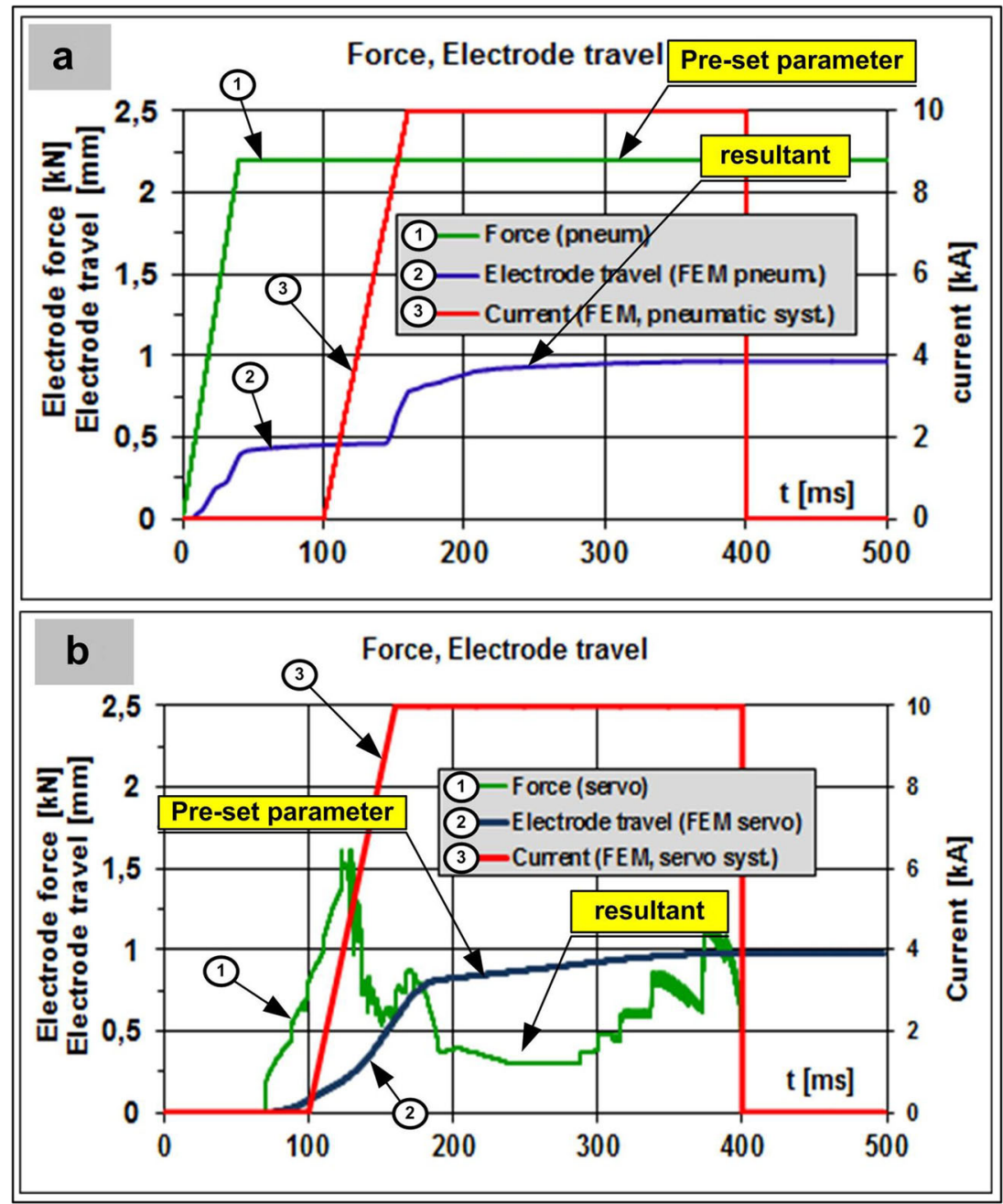

the welding process (Fig. 5b2). Also, the time of projection height reduction during the flow of current is desirably extended (Fig. 3, time $t_{s}$ ). The profile of electrode travel (i.e. the preset quantity) is presented in Fig. 6b. As a result of the new approach to the control of the process (electrode travel), it is possible to obtain the profile of force.

\section{Experimental verification}

The FEM calculation results were verified experimentally. The verification involved technological welding tests for various current flow times (c.f. Fig. 5) [9]. The technological tests were performed for both, i.e. the pneumatic and the electric servo electrode force system. The experimental results converged with the FEM calculation results (Fig. 7).

The electrode travel profiles confirm the existence of possible projection height reduction time extension during the flow of welding current. In the experimental conditions, this time was extended from $20 \mathrm{~ms}$ (pneumatic system) up to $90 \mathrm{~ms}$ (electric servo system) [9].

\section{Optimization of welding process}

The optimization of resistance projection welding of sheets with embossed projection should be started with characterization of mutual dependence between force and travel of electrodes. In the classical pneumatic force system, the constant force is preset. As the result, the travel of electrodes reduces the projection height (c.f. Fig. 6a). The parameter preset before the welding process (amplitude of current, current flow time and electrode force) influences on the final result. It should be noted that the control of electrode travel is impossible during welding (particularly during current flow). It results from undesired significant inertia of the pneumatic system. The narrow window of welding parameters and the force exceeding expected value are important drawback of such control method.

An alternative is to use the electric servo actuator and the appropriate (hybrid) algorithm of the control of electrode force and/or travel $[15,16]$.

Optimization process is illustrated by means of Fig. 8 . The profile A (no. 1) is treated as the beginning of optimization. 
Fig. 7 Comparison of the macrostructure of the projection welded joint made of DX53 steel (thickness

$\mathrm{g}=1.5+1.5 \mathrm{~mm}$ ) with FEM calculations for a pneumatic and b electric servo system in relation to the welding time (i.e. current flow time of $60 \mathrm{~ms}$ ) [9]
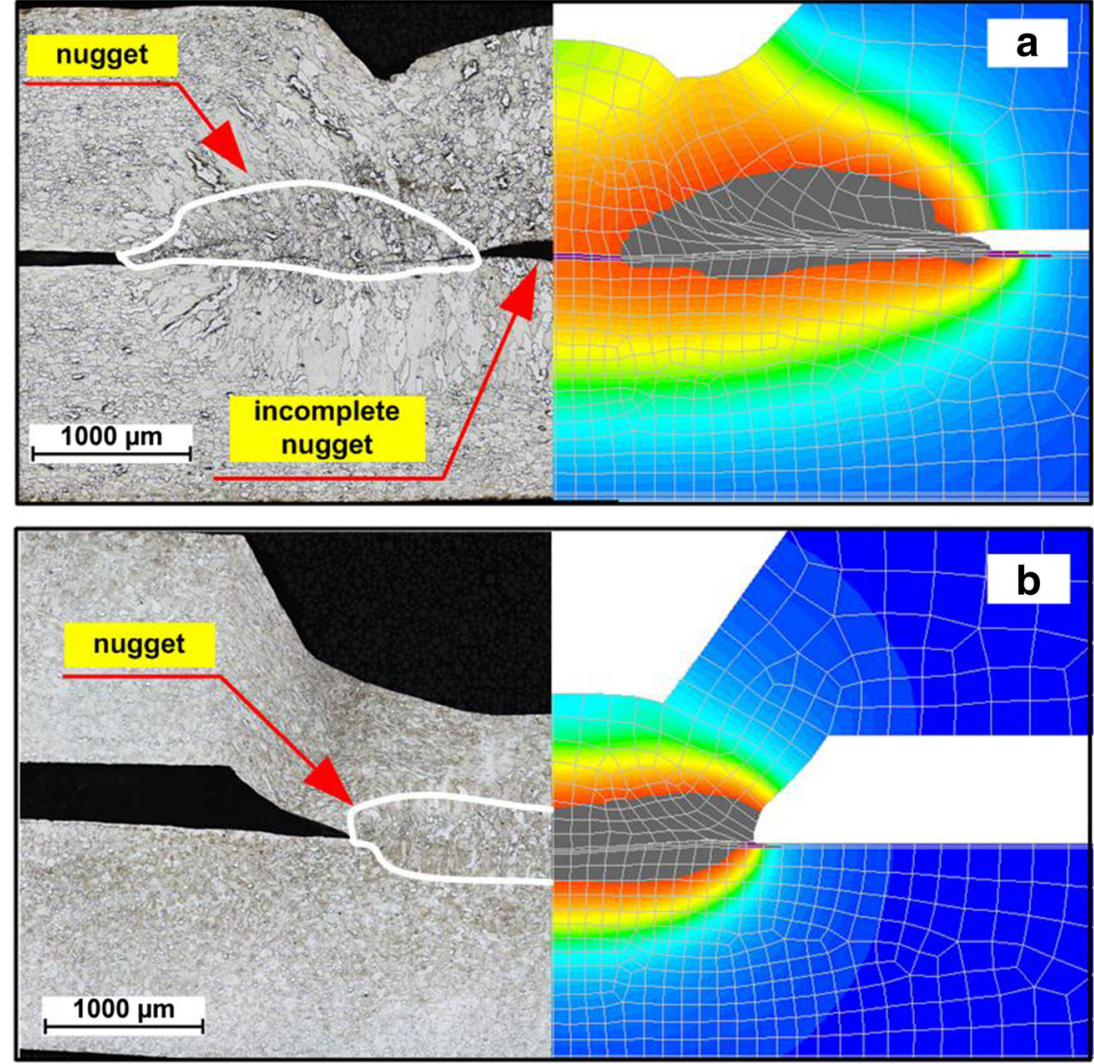

It has been obtained for the pneumatic force system (for the best welding conditions). The force in this case has constant value (c.f. Fig. 6a). Unfortunately, the value of force is too high. As a result, the projection height reduction before current flow is also too big $(0.45 \mathrm{~mm}$, e.g. $45 \%$ the initial projection height). In such case, the contact area between projection and second welded element (flat sheet) is too large. The contact resistance decreases (c.f. Fig. 4a), causing related power decreasing (c.f. Fig. 4b). Finally, the current density is too small and one can observe that the ring weld nugget is created.

The resistance welding process can be improved by slowing down (comparing to the classical pneumatic force system-profile A) the travel of electrode (c.f. Fig. 6b).
Fig. 8 Diagram of welding optimization in relation to the change of electrode travel profile

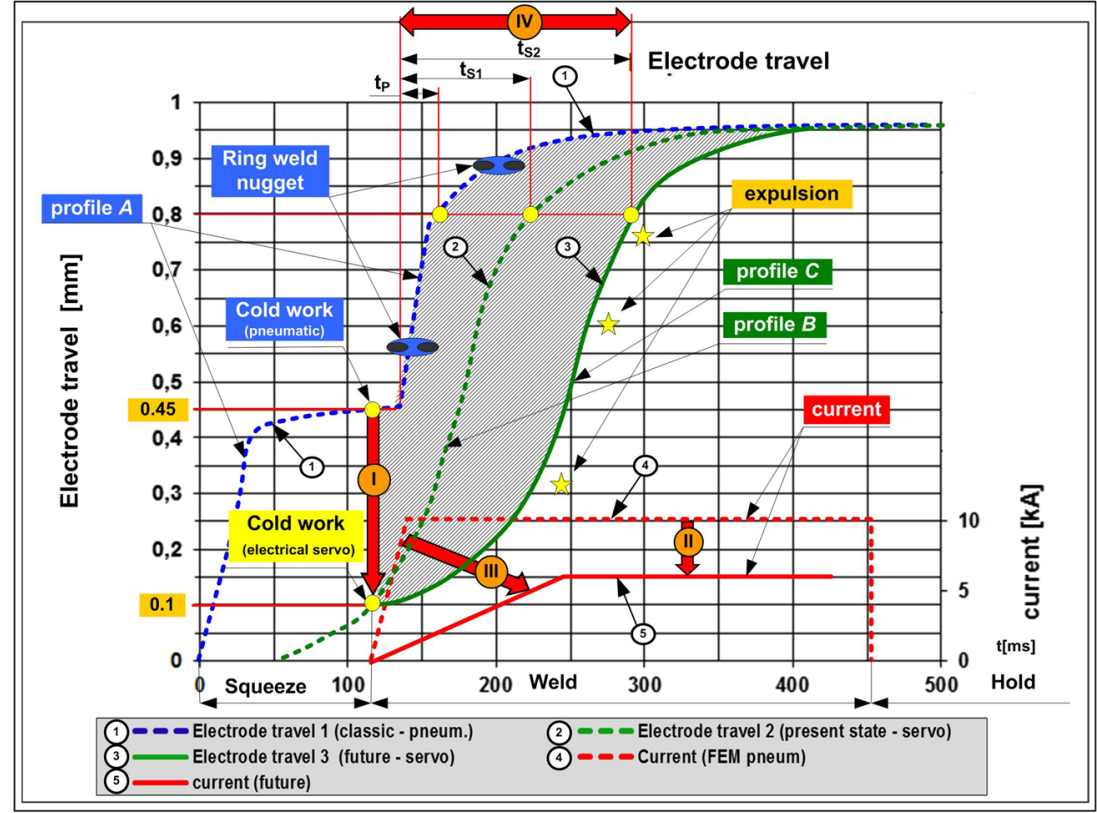


Profiles B (no. 2) and C (no. 3, c.f. Fig. 8) are the results of using electric servo actuator together with an appropriate control algorithm of electrode force and/or travel.

The first stage of optimization (profile B) realized using the electric servo actuator with proper (hybrid) algorithm of electrode force and/or travel control is obtained by applying the same welding parameters (amplitude and time of welding current) as for a pneumatic system. As the result in the first technological interval IF (i.e. initial force), the smaller projection height reduction is obtained at the beginning of the process (cold work). The projection height reduction $0.1 \mathrm{~mm}$ ( $10 \%$ of the initial projection height) is much more smaller in comparison with the projection height reduction obtained with the pneumatic system $(0.45 \mathrm{~mm}$, i.e. $45 \%$ of the initial projection height). The contact area between the projection and the second welded element is smaller, whereas the resistance of the contact area is higher (c.f. Fig. 4a), and the same time-related power of welding area is also higher (c.f. Fig. 4b).

In the second technological interval MI (c.f. Fig. 8), the travel of electrode is controlled instead of force control. Remaining part of profile B is determined as a limit of the lack of liquid metal expulsion. The result of such control method is higher power and energy supplied to the weld in the whole welding area (c.f. Fig. 4b). What is important, at the beginning of current flow, the material of projection is melted in the proper place, namely in the projection cup (c.f. Fig. 5b2). During the current flow, the weld nugget is initiated in the center and grew outwards (c.f. Fig. $5 b(2-7)$ ). The control of electrode travel during the flow of the current and the lower value of electrode force applied before the current flow results in a significantly longer time of projection height reduction $t_{S 1}$ (approximately $90 \mathrm{~ms}$ ). In the case of the classical system (the pneumatic electrode force-profile A), the time of projection height reduction $\left(t_{P}\right)$ is too small (about $20 \mathrm{~ms}$ ). The time of projection height reduction significantly affects generation of welding power in the most convenient place (i.e. in the embossed projection). In spite of the lower welding current, the extension of projection height reduction time led to the generation of greater welding power in the projection material [9]. The optimization performed by the authors made it possible to double the energy generated in the projection $[9,15]$.

The next step of optimization is the reduction of amplitude of the welding current and the extension of the up-slope (i.e. current increase) time resulting in the longest time of projection height reduction $\left(t_{S 2}\right)$ during the flow of welding current (electrode travel profile $\mathrm{C}$ ). Profile $\mathrm{C}$ requires further research. The curves of electrode travel presented in Fig. 8, that are profiles A, B and C, have been determined numerically. Profile A and profile $B$ has been verified experimentally in the whole range of welding time (current flow time) [9]. As the example of the experimental verification of FEM results presented in Fig. 5a2 and b2, the temperature distribution (the beginning of the current flow- $60 \mathrm{~ms}$ ) is presented in Fig. 7.

The criterion of the optimization has been assumed as the same full weld nugget diameter and weld strength as those obtained using the pneumatic force system [20].

\section{Conclusion}

The direction of changes resulting from the use of the electric servo actuator and the algorithm of electrode force and travel control differs significantly from those adopted previously (Fig. 9). The activities undertaken by the authors resulted in the obtainment of both surprising and advantageous effects confirmed experimentally.

The fundamental difference between the two systems described in the paper is method for control of electrodes travel/force. In the pneumatic system, the force is applied and the travel is the result. In the case of electric servo system and the new (hybrid) control algorithm, applied quantity is the electrode travel (during the current flow) and the force is a result. The second system is characterized by slower displacement (lower velocity of electrode travel) than the first one.

Presented in the paper innovative method of control of electrode travel can influence on the previously existing approach to resistance welding and revolutionize the development of this scientific and technological area. The control used up to date was an open-loop control. The travel of electrodes was controlled basing on given travel profile without a feedback.

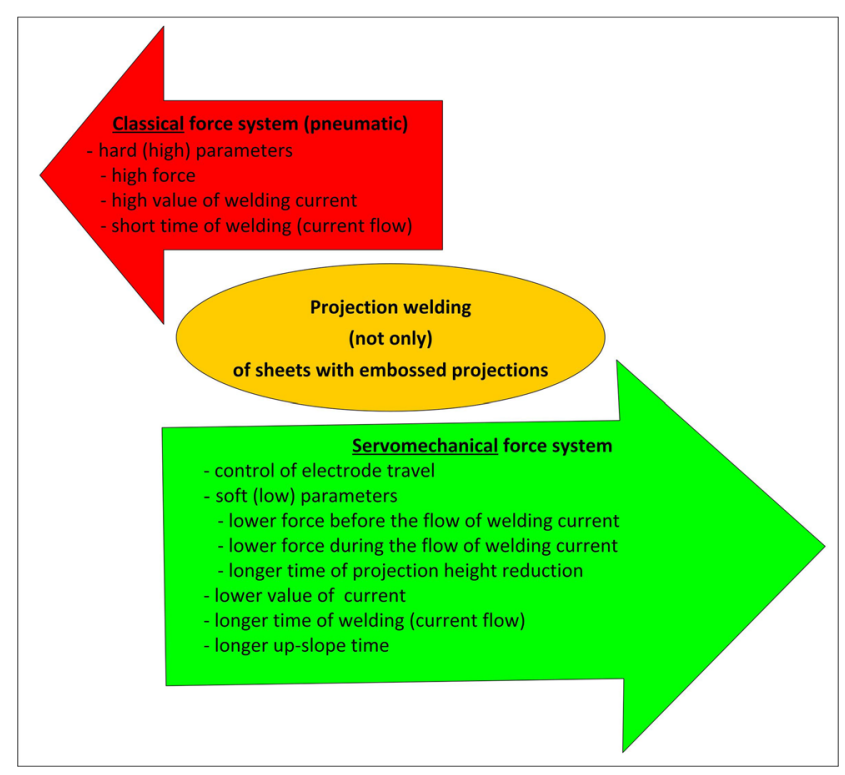

Fig. 9 Welding process optimization diagram 
The authors carried out several tests and analyses of various parameters, including the energy supplied to the weld, the instantaneous power waveform, the resistance waveform and the course of force in order to determine the best (i.e. the most efficient) parameter, in relation to which the control process can be performed.

Acknowledgments The work reported in the paper is supported by Polish National Center of Science under the research projects with contract no. TANGO1/267374/NCBR/2015.

Open Access This article is distributed under the terms of the Creative Commons Attribution 4.0 International License (http:// creativecommons.org/licenses/by/4.0/), which permits unrestricted use, distribution, and reproduction in any medium, provided you give appropriate credit to the original author(s) and the source, provide a link to the Creative Commons license, and indicate if changes were made.

\section{References}

1. Mikno Z, Papkala H, Piatek M (2004) Monitoring and control in resistance welding process. quality, development, competitiveness and future (in Polish) in Resistance welding - history, present, future. Seminar proceeding of Institute of Welding, March 2004 pp 5

2. Jiang J (2011) The price of electricity in your state. U.S. Energy information administration, Published October 282011

3. Mikno Z, Stepien M (2016) Highly efficient invertor welder machine with increased frequency - advantages and profits of novel technology (in Polish). Bulletin of Welding Institute (Biuletyn Instytutu Spawalnictwa) 5/2016 pp 69-73

4. Mikno Z, Bartnik Z, Lange A, Sikorski M (2012) Selected aspect of steel sheets projection welding in FEM calculations (in Polish). Welding Review (Przeglad Spawalnictwa) 10:65-71

5. Larson J (2008) Projection welding for nut and bolt attachment. The Fabricator, Feb. 2008

6. Sun B (2001) Effect of projection height on projection collapse and nugget formation - a finite element study. Supplement to the welding journal, September 2001
7. Mikno Z, Bartnik Z, Derlukiewicz W, Kowieski S (2013) Projection Welding by FEM Calculations (in Polish). Welding Review (Przeglad Spawalnictwa) 11:64-70

8. Welding Projection (2016) Welding technology corp. Last access March 12, 2016

9. Mikno Z (2016) Projection Welding with Pneumatic and Servomechanical Electrode Operating Force Systems. WELD J (Welidng Research) vol 95, August pp 286-299

10. Huanga H, Tseng K (2009) Process parameters in resistance projection welding for optical transmission device package. $\mathrm{j}$ MATER ENG PERFORM, June 18, 2009

11. Gould JE (2012) Joining aluminum sheet in the automotive industry - a 30 year history. Weld J (Welidng Research) 91:2334

12. Senkara J (2011) Resistance Welding: Fundamentals and Applications. CRC Taylor \& Francis

13. Zhang X, Chen G, Zhang Y, Lai H (2009) Improvement of resistance spot weldability for dual-phase (DP600) steels using servo gun. J Mater Process Tech

14. Agapiou JS, Perry TA (2013) Resistance Mash welding for joining of copper conductors for electric motors. J Manuf Process 15(4):549-557

15. Mikno Z, Bartnik Z, Ambroziak Z, Pietras A (2012) Method for Projection Resistance Welding of Steel Plates with Embossed Projections. Patent P. 401723 Polish Patent Office

16. Mikno Z, Pietras A, Grzesik B, Stepien M (2015) Polish patent (pending) P.412615 A manner of resistance projection welding in congiguration of the cross, mainly for aluminum bars. Polish Patent Office

17. SORPAS User Manual (2015) Swantec Inc. SORPAS Software Ver. 11.2

18. Projection Welding (2001) Welding Handbook, 9th Ed., Vol. 3, Part 2: Welding Processes, American Welding Soc

19. Gould JE (1993) Projection welding. ASM handbook, vol. 6: welding, Brazing, and Soldering, ASM International (USA), pp 230-237

20. Mikno Z, Stepien M, Grzesik B (2015) Optimising the operation of servomechanical force systems used in the joining of thinwalled metal elements in the automotive industry. International Conference on Sustainable Mobility Applications, Renewables and Technology (SMART), November 23-25 2015, Kuwait City. Kuwait 